\title{
Author Correction: Excitotoxic inactivation of constitutive oxidative stress detoxification pathway in neurons can be rescued by PKD1
}

Julia Pose-Utrilla1,2, Lucía García-Guerra1,2, Ana Del Puerto1,2, Abraham Martín³, Jerónimo Jurado-Arjona 2,4,12, Noelia S. De León-Reyes ${ }^{1,13}$, Andrea Gamir-Morralla,2,12, Álvaro Sebastián-Serrano ${ }^{1,2}$, Mónica García-Gallo5, Leonor Kremer ${ }^{5}$, Jens Fielitz ${ }^{6,7}$, Christofer Ireson ${ }^{8,14}, M^{a}$ José Pérez-Álvarez ${ }^{2,4,9}$, Isidro Ferrer ${ }^{2,10,}$ Félix Hernández ${ }^{2,4}$, Jesús Ávila ${ }^{2,4}$, Marina Lasa ${ }^{1}$, Miguel R. Campanero ${ }^{1,11}$ \& Teresa Iglesias (1) 1,2

Correction to: Nature Communications https://doi.org/10.1038/s41467-017-02322-5, published online 22 December 2017

The original version of this Article contained an error in the spelling of the author Álvaro Sebastián-Serrano, which was incorrectly given as Álvaro Sebastián Serrano. This has now been corrected in both the PDF and HTML versions of the Article.

Published online: 30 January 2018

Open Access This article is licensed under a Creative Commons Attribution 4.0 International License, which permits use, sharing, adaptation, distribution and reproduction in any medium or format, as long as you give appropriate credit to the original author(s) and the source, provide a link to the Creative Commons license, and indicate if changes were made. The images or other third party material in this article are included in the article's Creative Commons license, unless indicated otherwise in a credit line to the material. If material is not included in the article's Creative Commons license and your intended use is not permitted by statutory regulation or exceeds the permitted use, you will need to obtain permission directly from the copyright holder. To view a copy of this license, visit http://creativecommons.org/licenses/by/4.0/.
\end{abstract}

(C) The Author(s) 2018

\footnotetext{
${ }^{1}$ Instituto de Investigaciones Biomédicas "Alberto Sols", Consejo Superior de Investigaciones Científicas-Universidad Autónoma de Madrid (CSIC-UAM), C/ Arturo Duperier 4, 28029 Madrid, Spain. ${ }^{2}$ CIBERNED, Centro de Investigación Biomédica en Red sobre Enfermedades Neurodegenerativas, Instituto de Salud Carlos III, C/ Valderrebollo, 5, 28031 Madrid, Spain. ${ }^{3}$ Experimental Molecular Imaging (Molecular Imaging Unit), CIC biomaGUNE, Paseo Miramon, 182, 20009 San Sebastian, Spain. ${ }^{4}$ Centro de Biología Molecular "Severo Ochoa" (CSIC-UAM), C/ Nicolas Cabrera 1, 28049 Madrid, Spain. 5 Protein Tools Unit, Centro Nacional de Biotecnologia, Consejo Superior de Investigaciones Científicas (CSIC), C/ Darwin 3, 28049 Madrid, Spain. ${ }^{6}$ Experimental and Clinical Research Center (ECRC), Charité-Universitätsmedizin, Max-Delbrück-Center (MDC) for Molecular Medicine in the Helmholtz Association, 13125 Berlin, Germany. ${ }^{7}$ Department of Cardiology, Heart Center Brandenburg and Medical University Brandenburg (MHB), 16321 Bernau, Germany. ${ }^{8}$ Cancer Research Technology, EC1V 4AD London, UK. ${ }^{9}$ Departamento de Biología (Unidad Docente Fisiología Animal), UAM, C/ Darwin 2, 28049 Madrid, Spain. ${ }^{10}$ Instituto de Neuropatología, Hospital Universitario de Bellvitge, C/ Feixa LLarga s/n, 08907 Barcelona, Hospitalet de Llobregat, Spain. ${ }^{11}$ CIBERCV, Centro de Investigación Biomédica en Red de Enfermedades Cardiovasculares, Instituto de Salud Carlos III, 28029 Madrid, Spain. ${ }^{12}$ Present address: Institute of Physiological Chemistry, University Medical Center, Johannes Gutenberg University Mainz, Hanns-Dieter-Hüsch-Weg 19, 55128 Mainz, Germany. ${ }^{13}$ Present address: Centro Nacional de Biotecnología (CSIC), C/ Darwin 3, 28049 Madrid, Spain. ${ }^{14}$ Present address: Pharmidex Pharmaceutical Services, 14 Hanover Street, W1S 1YH London, UK. Julia Pose-Utrilla and Lucía García-Guerra contributed equally to this work. Correspondence and requests for materials should be addressed to T.I. (email: tiglesias@iib.uam.es)
} 